\title{
Análise Profissiográfica e Mapeamento de Competências nas Instituições de Segurança Pública
}

\section{Análise Profissiográfica e Mapeamento na} Segurança Pública

Análisis Profisiográfico y Mapeo en la Seguridad Pública
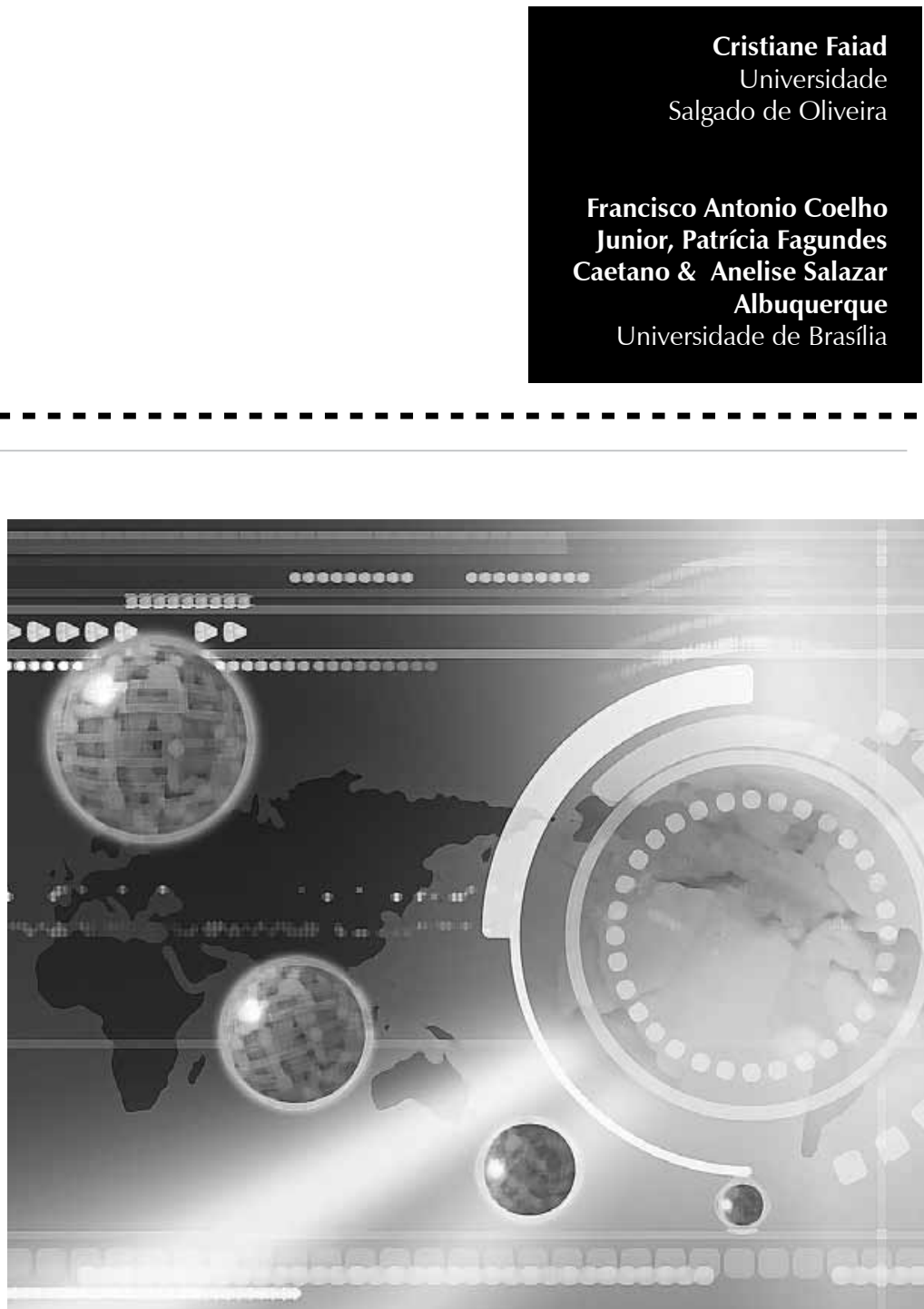
Resumo: A profissionalização contínua da qualidade dos serviços prestados à comunidade pelas instituições de segurança pública vem sendo impulsionada pela aplicação de princípios e práticas de recursos humanos e de gestão de pessoas no trabalho. Tais práticas dizem respeito à definição das atribuições e responsabilidades de um cargo em consonância com o perfil de competências exigido para o desempenho do mesmo. Importantes fontes de insumo a essas práticas dizem respeito à aplicação da profissiografia e do mapeamento de competências à realidade das instituições de segurança pública, importantes para o planejamento de ações voltadas para o desenvolvimento das pessoas e para a busca pelo desempenho competente. Este trabalho objetiva discutir questões de natureza metodológica e implicações práticas decorrentes da aplicação dessas ferramentas, análise profissiográfica e mapeamento de competências em instituições policiais, apontando limites e possibilidades no contexto da segurança pública. Efetuou-se um levantamento bibliográfico nos principais periódicos nacionais de administração e de Psicologia, visando, a partir de análise das publicações sobre o tema, a propor um método destinado ao mapeamento profissiográfico e de competências e à sua análise crítica em termos de aplicabilidade no contexto das organizações. Apresentam-se, aqui, possibilidades de atuação na área da segurança pública, integrando-se as técnicas de mapeamento de profissiografia.

Palavras-chave: Profissiografia. Competência profissional. Segurança pública. Administração de recursos humanos.

Abstract: Continuous professionalization of the quality of the services provided to the community by the public security institutions has been propelled by the application of practices and principles from human resources and management of people at work. Such practices refer to the definition of duties and responsibilities of a post in accord with the competency profile required for the performance of the post. Important sources of input to the referred practices regard the application of professional profiling and of competency mapping to the reality of the public security institutions, vital to the planning of personnel development actions and to the quest for competent performance. The present work aims at discussing issues of methodological nature and the practical implications deriving from the application of these tools, namely, professional profiling and competency mapping, in law enforcement institutions, indicating the limits and the possibilities in the context of public security. The bibliographic study of the main national administration and psychology periodicals was conducted with the view of proposing a method for competency and professional profile mapping and its critical analysis in terms of applicability within the reality of the organizations, based on the analysis of the publications on the theme. Possibilities are presented herein for the acting in the context of public security, integrating the techniques of professional profile mapping.

Keywords: Job analysis. Professional competence. Public security. Human resources administration.

Resumen: La profesionalización continuada de la calidad de los servicios rendidos a la comunidad por las instituciones de seguridad pública ha sido impulsada por la aplicación de principios y prácticas de recursos humanos y de gestión de personas en el trabajo. Dichas prácticas dicen respecto a la definición de las atribuciones y responsabilidades de un cargo en consonancia con el perfil de competencias exigido para el desempeño de ese cargo. Importantes fuentes de insumo a esas prácticas dicen respecto a la aplicación de la profisiografía y del mapeo de competencias a la realidad de las instituciones de seguridad pública, importantes para la planeación de acciones destinadas al desarrollo de las personas y a la búsqueda por el desempeño competente. Este trabajo tiene como objetivo discutir cuestiones de naturaleza metodológica e implicaciones prácticas decurrentes de la aplicación de esas herramientas, análisis profisiográfico y mapeo de competencias en instituciones policíacas, señalando límites y posibilidades en el contexto de la seguridad pública. Se ha efectuado un levantamiento bibliográfico en los principales periódicos nacionales de administración y de Psicología, objetivando, a partir de un análisis de las publicaciones acerca del tema, proponer un método destinado al mapeo profisiográfico y de competencias y a su análisis crítico en términos de aplicabilidad en el contexto de las organizaciones. Se presentan, aquí, posibilidades de actuación en el área de seguridad pública, integrándose las técnicas de mapeo de profisiografía.

Palabras clave: Profisiografía. Competencia profesional. Seguridad pública. Administracion de personal.

Na era da globalização da economia, as exigências por qualidade, produtividade e inovação constante de produtos e serviços têm aumentado significativamente, pressionando as organizações a acompanhar o ritmo imposto pelos países do Primeiro Mundo na corrida pela participação no mercado. A complexidade crescente das organizações exige que os seus gestores desenvolvam competências que lhes permitam diagnosticar, de forma integrada e eficaz, os problemas organizacionais com os quais se defrontam e 


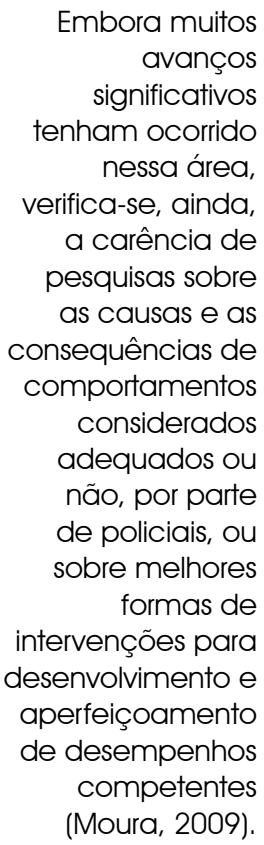

desenvolver as correspondentes estratégias de mudança. O Brasil, também, está empenhado em seu desenvolvimento social e econômico. Contudo, apesar desse esforço, é preciso que inúmeros problemas relacionados à gestão organizacional ou de cunho técnico e administrativo sejam enfrentados. Diante desse contexto, empresas públicas e privadas passaram a reconhecer que a sobrevivência e o desenvolvimento organizacional dependem, primordialmente, dos profissionais que nelas trabalham. Por meio do capital humano, as empresas são capazes de lidar com frequentes mudanças e inovações, bem como de agregar valores aos clientes, mantendo-se, com isso, eficazes e competitivas no atual mundo globalizado e fortemente competitivo. Nesse sentido, é possível constatar que os profissionais adquiriram, ao longo dos tempos, importância tática e estratégica e que estão associados à busca contínua pela excelência organizacional.

O recrutamento e a seleção de profissionais capazes, com perfil esperado para o desempenho das funções, tornam-se, então, as estratégias de recursos humanos mais importantes para as organizações, visto que agregam indivíduos com potencial para contribuir com o alcance da missão e dos objetivos organizacionais. Faz-se mister conhecer, de forma válida, precisa e fidedigna, o conjunto de cargos, áreas e funções que compõem a estrutura de uma empresa e, mais especificamente, o conjunto de competências demandadas ao bom desempenho dos mesmos.

A avaliação psicológica é uma das ferramentas utilizadas na realização de processos seletivos. Ramon (1992) afirma que, com a regulamentação da Psicologia, na década de 60 , houve um aumento significativo do número de empresas interessadas em investir nos processos de recrutamento e seleção de pessoas. Dessa forma, a avaliação psicológica passou a ser bastante utilizada por psicólogos e difundida como uma técnica capaz de aumentar a probabilidade de identificar o candidato mais adequado ao cargo em termos da promoção de seu desempenho competente.

Assim, em processo de seleção de pessoal realizado por meio de avaliação psicológica, é possível coletar informações sobre as características dos candidatos ao cargo de modo a compará-las com os atributos que formam o perfil do cargo, ou seja, com as características necessárias ao bom desempenho em cada tarefa. Nos concursos públicos, o mesmo princípio é utilizado, ou seja, necessita-se de uma análise do cargo, o que inclui o estudo das tarefas do cargo e dos requisitos psicológicos necessários para o bom desempenho de suas tarefas, para então realizar o mapeamento e a análise das características dos candidatos por meio da aplicação de instrumentos validados e precisos.

Pesquisas na área de avaliação psicológica relacionadas especialmente às avaliações dos comportamentos de policiais no contexto da segurança pública têm sido cada vez mais necessárias no cenário mundial e, em particular, no Brasil. Embora muitos avanços significativos tenham ocorrido nessa área, verifica-se, ainda, a carência de pesquisas sobre as causas e as consequências de comportamentos considerados adequados ou não, por parte de policiais, ou sobre melhores formas de intervenções para desenvolvimento e aperfeiçoamento de desempenhos competentes (Moura, 2009).

Considera-se a premissa básica de que a atividade policial requer um conjunto de características, sobretudo atitudinais e psicológicas, complexas e de difícil mensuração. De forma geral, essa necessidade tem causado uma série de controvérsias e litígios na etapa de avaliação psicológica de concursos públicos para cargos policiais. 
Diante desse contexto, observa-se a necessidade de se avaliar, primeiramente, quais são os reais requisitos psicológicos que devem ser apresentados por um candidato a um cargo policial e, ainda, identificar de que forma determinadas características pessoais e/ou profissionais podem influenciar no processo de adaptação e no desempenho desse profissional a partir de seu ingresso em instituições de segurança pública.

Em pesquisas na literatura sobre comportamento organizacional, salvo algumas exceções, como em Brandão e Borges-Andrade (2007), não foram encontradas referências que propusessem algum tipo de técnica ou método orientado para o mapeamento e o diagnóstico de competências que pudesse ser aplicado na área de segurança pública, ainda mais alinhada à realização da atividade de profissiografia. No contexto de cargos policiais, então, não se verificou nenhuma publicação científica relacionada a esse objetivo.

O presente trabalho objetiva discutir questões de natureza metodológica e implicações práticas decorrentes da aplicação dessas ferramentas, análise profissiográfica e mapeamento de competências, em instituições policiais, apontando os limites e as possibilidades no contexto da segurança pública. Para tal, efetuou-se um levantamento bibliográfico nos principais periódicos nacionais de administração e de Psicologia, visando, a partir da análise de publicações sobre o tema, a propor um método voltado para o mapeamento profissiográfico e de competências e sua análise crítica em termos de aplicabilidade na realidade das organizações.

\section{Revisão de literatura}

Alguns estudos profissiográficos na área de segurança pública já foram realizados no
Brasil (por exemplo, Freitas, 2004; Moura \& Caetano, 2007; Moura, Caetano, Braga, Pasquali, Reis, \& Oliveira, 2007; Pasquali, Cabral, Figueira, Rodrigues, \& Moura, 2002; Pasquali, Albuquerque, Freitas, Barbosa, \& Roldão, 2002; Thadeu, Reis, Moura, Caetano, Braga, \& Pasquali, 2008), e os dados indicaram que algumas características individuais ou requisitos psicológicos são necessários, senão primordiais, para uma adaptação adequada do indivíduo ao contexto da natureza de suas atividades e da organização como um todo. Algumas dessas características dizem respeito ao grau de domínio que o indivíduo deve apresentar acerca de conhecimentos, habilidades e atitudes necessárias à produção de resultados efetivos em seu trabalho.

Em alguns desses estudos, foram elencadas as competências técnicas e comportamentais requeridas para o bom desempenho de atividades no trabalho, além de traços de personalidade considerados imprescindíveis à facilitação do desempenho. Entre essas características, encontram-se, por exemplo, o nível de agressividade, as habilidades específicas, a inteligência, as características de personalidade e as competências relativas à execução do trabalho, dentre vários outros requisitos, pessoais e profissionais, que são identificados como adequados ao cargo policial ou, mesmo, para a manutenção da Saúde Mental desse profissional. Considera-se que, certamente, essa realidade não se aplica apenas a organizações de segurança pública, mas a diversas outras de distintas naturezas e finalidades, embora as primeiras sejam objeto do presente estudo.

É notório que o investimento no planejamento do sistema de segurança pública no Brasil, bem como na área da Justiça criminal, tem sofrido grande pressão social, especialmente no que tange ao desempenho de suas funções constitucionais, aliado à crescente onda de violência e criminalidade (SENASP, 2008). A literatura disponível em administração, 
em Psicologia social e em Sociologia vem destacando a influência de fatores relacionados à tarefa e ao contexto de trabalho no desempenho competente desses indivíduos. Entretanto, Pasquali, Moura e Freitas (2010) apontam a necessidade de maiores investimentos na área de segurança pública, especialmente a realização de estudos científicos dentro dessas organizações, objetivando o aprimoramento permanente de seus membros e a compreensão real de suas demandas.

Dentre as ferramentas e os processos de gestão e de intervenção que podem auxiliar as instituições de segurança pública, destacamse a análise profissiográfica e o mapeamento de competências. Esses dois tipos de metodologia se destacam, atualmente, por possibilitar um estudo sistemático de todo o processo de trabalho referente a cada cargo de uma instituição. Pasquali, Moura e Freitas (2010) afirmam que pesquisas dessa natureza podem viabilizar diversos processos nas organizações, incluindo o planejamento do trabalho estratégico, e servir como base para práticas relacionadas a políticas de seleção de pessoas, treinamento, avaliação de desempenho, encarreiramento e análise da estrutura de cursos de formação, dentre outras.

Coelho Jr., Moura, Caetano e Albuquerque (2009) identificaram doze diferentes contribuições que um produto de análise profissiográfica e mapeamento de competências podem trazer para as instituições, como, por exemplo, o provimento de subsídio para cursos de capacitação e formação, a partir de um levantamento prévio das tarefas (importância, frequência e dificuldade de execução das tarefas) como diagnóstico para maiores necessidades de treinamento para os cargos, bem como a identificação das competências (por importância e domínio de repertório) a serem trabalhadas, e avaliação de desempenho focada no cargo e por meio de competências, com foco no planejamento do trabalho e na organização racional das atividades. Outra contribuição diz respeito à obtenção de indicadores de análise para suporte ou apoio às ações de acompanhamento biopsicossocial dos servidores, no que tange a projetos de qualidade de vida ou mesmo, especificamente, à promoção do desenvolvimento profissional do ocupante do cargo.

O mapeamento de competências, se devidamente implementado e revisado, também deve servir de insumo à consolidação do perfil profissiográfico do cargo, especialmente no que se refere à indispensabilidade do mesmo no desenvolvimento de ações de aprendizagem, formal ou informal, no trabalho (Coelho Jr. \& Borges-Andrade, 2008), visando a otimizar o desempenho competente, isso porque o mapeamento fornece insumos ao desenho de ações de educação continuada à medida que identifica necessidades de treinamento que os ocupantes necessitem desenvolver para o exercício competente de suas atribuições, ou mesmo fatores de contexto que precisam ser removidos visando ao estímulo ao apoio e suporte à aprendizagem. Até em virtude disso, torna-se premente o monitoramento e a avaliação contínuos, tanto do mapeamento realizado quanto do seu alinhamento ao perfil profissiográfico do cargo, a fim de que os mesmos não se tornem engessados e anacrônicos em relação à dinâmica organizacional.

\section{Análise profissiográfica}

A profissiografia, ou análise profissiográfica, é considerada um tipo de proposta metodológica que tem como objetivo norteador o levantamento do perfil profissiográfico de um determinado cargo, ou seja, realizar uma análise detalhada de suas características e peculiaridades (Brannick, Levine, \& Morgeson, 
2002; Pasquali, Moura, \& Freitas, 2010). Essa metodologia tem como diferencial de outras técnicas a centralidade na amostra estudada, ou seja, quando os dados coletados são indicados para a população ocupante do cargo, e não por poucos ocupantes do mesmo. Espera-se que, no mínimo, uma amostra representativa de grande parte dessa população seja avaliada com base nos dados coletados, de modo a garantir a representatividade e a fidedignidade das análises realizadas (Pasquali et al., 2010).

A análise profissiográfica teve origem nos processos de intervenção de Emílio Mira y Lopez, no Instituto de Seleção e Orientação Profissional - ISOP, no ano 1964. Esse autor conceituou o estudo profissiográfico como um processo "destinado ao conhecimento dos normotipos profissionais" (1955, p. 208 como citado em Sampaio, 2006). Nessa época, Mira y Lopez já articulava os critérios de análise profissiográfica como fonte de estudo do cargo, como descrição e hierarquização da importância da análise entre o trabalho e seu ambiente (Sampaio, 2006). Já a proposta metodológica de análise profissiográfica apresentada no presente artigo teve origem em uma intervenção na área de educação (Pasquali, 1997). Contudo, no ano 2004, houve uma reestruturação da metodologia por um grupo de pesquisadores e psicólogos, que a vêm aplicando, desde então, em diversas instituições de segurança pública no Brasil.

De acordo com Dezinot (2003), o perfil profissiográfico possui uma abrangência muito maior que uma simples descrição de cargos, posto que aprofunda e detalha, em termos de pré-requisitos, as especificações necessárias ao desempenho competente das tarefas e atribuições. Sendo assim, pode-se dizer que a profissiografia é desenvolvida por meio de um criterioso trabalho de descrição de cargos, que deve ter cada uma de suas tarefas descritas pormenorizadamente.
Spector (2003) distingue dois diferentes tipos de análise de cargo ou do trabalho; a primeira é definida como análise orientada ao trabalho e enfoca as tarefas que são realizadas na atividade, conhecida na prática como a descrição do cargo; a segunda é orientada para a pessoa que executa a tarefa, indicando os atributos, as características ou mesmo os conhecimentos e as habilidades necessários para desenvolver, com êxito, um trabalho, sendo o foco nas características pessoais requeridas para um determinado cargo. Assim, as duas análises propostas são necessárias para a compreensão do cargo, sendo que a análise profissiográfica abarca esses dois processos.

$\mathrm{Na}$ busca pela compreensão do cargo e de seus ocupantes, o Decreto no 7.308, de 22 de setembro de 2010, implementou as regras para a realização de avaliações psicológicas em candidatos a cargos federais, incluindo a área de segurança pública:

§ 3o "Os requisitos psicológicos para
o desempenho no cargo deverão ser
estabelecidos previamente, por meio
de estudo científico das atribuições e
responsabilidades dos cargos, descrição
detalhada das atividades e tarefas,
identificação dos conhecimentos, habilidades
e características pessoais necessários para sua
execução e identificação de características
restritivas ou impeditivas para o cargo" (p.1)

Diante disso, o perfil profissiográfico se tornou uma das ferramentas mais utilizadas para seleção e formação de policiais no Brasil, representando mais do que a simples descrição de cargos e funções dentro da organização. Por meio da análise profissiográfica, obtém-se um estudo detalhado de todas as tarefas de um determinado cargo ou função, com especificação do nível de dificuldade, importância e frequência com que elas ocorrem. Nesse sentido, serve como instrumento auxiliar não só no processo seletivo como também no curso de formação, na medida em que possibilita a determinação 
A gestão por competências emerge e se consolida como uma tecnologia alternativa

aos modelos tradicionalmente utilizados

para mapear

e promover ações de desenvolvimento contínuo no trabalho (Brandão \& Guimarães, 2001). dos aspectos mínimos a serem abordados nas disciplinas ministradas para busca do policial que mais se aproxime do exigido pela instituição e pela sociedade.

No que se refere ao indivíduo, o perfil profissiográfico indica as características pessoais necessárias ao bom desempenho do cargo em questão, assim como as restritivas ou impeditivas. Dessa forma, pode ser ainda utilizado na determinação de critérios avaliativos, auxiliando a área de treinamento e a capacitação da organização, já que determina, claramente, quais atividades devem ser desenvolvidas e quais as características esperadas do policial.

Apesar dos estudos incipientes nessa área, como o de Freitas (2004), Vasconcelos (2010), Thadeu (2011) e Ávila-Batista (2011), algumas seleções de pessoal na área de segurança pública ainda carecem de critérios científicos para embasar seus processos. A partir da vigência do Decreto $\mathrm{n}$ 7.308, o uso de uma metodologia científica aplicada adequadamente em processos seletivos é o único meio de definir quais serão as reais qualificações necessárias aos candidatos aos cargos, de maneira que os candidatos eventualmente selecionados venham a executar suas futuras funções com relativo sucesso. Nesse sentido, a análise profissiográfica é pautada nos cânones e nos pressupostos fundamentais da ciência, e permite o estabelecimento de um perfil fidedigno e validado a partir de dados obtidos com a própria população de ocupantes do cargo.

O estudo científico está contemplado na busca pela sistematização metodológica que permita identificar dados válidos e relevantes sobre o cargo. Sendo assim, a descrição simples de tarefas do cargo, bem como o levantamento de requisitos informalmente elencados, não caracteriza ou sintetiza essa proposta. A análise profissiográfica, conforme proposta por Pasquali et al. (2010), estabelece a necessidade de se ter um cuidado com a representatividade dos dados, que vai trazer relevância, validade externa e consistência aos mesmos. Além de toda essa preocupação com a validade empírica das informações coletadas sobre o cargo, é importante que se faça uma análise contingencial da organização antes mesmo de se planejar a investigação dos atributos do cargo. Não se trata de uma proposta simplista de se colocar o homem certo no lugar certo, mas de se pensar no indivíduo com maior probabilidade de se adaptar ao contexto de trabalho em que será inserido com base na compatibilidade entre suas características pessoais e as demandas do cargo pleiteado. Por isso, a compreensão das influências dos contextos organizacionais no desempenho do trabalhador é fundamental nessa metodologia.

\section{Mapeamento de competências}

A gestão por competências emerge e se consolida como uma tecnologia alternativa aos modelos tradicionalmente utilizados para mapear e promover ações de desenvolvimento contínuo no trabalho (Brandão \& Guimarães, 2001). Baseando-se no pressuposto de que o domínio de certos recursos é condicionante do desempenho organizacional, a gestão de competências se propõe a integrar e a orientar esforços, sobretudo os relacionados à gestão de pessoas, visando a desenvolver e a sustentar os atributos considerados fundamentais à consecução dos objetivos e da missão organizacional (Durand, 1998; Prahalad \& Hamel, 1995).

A gestão por competências está inserida em uma proposta de otimização do desempenho organizacional e profissional, na compreensão de que o domínio de certas competências necessárias para o desempenho de tarefas de um cargo (Brandão \& Borges-Andrade, 2007; Brandão \& Guimarães, 2002; Dutra, 
Hipólito, \& Silva, 2000) é facilitador de resultados efetivos para a organização. Assim, conhecimentos, habilidades e atitudes são considerados, na literatura em comportamento organizacional, facilitadores ao desempenho competente a partir da mobilização dessas competências nas rotinas por meio da entrega de produtos relacionados ao trabalho.

O mapeamento de competências consiste na identificação e na operacionalização das competências, no nível individual, existentes na organização. A descrição é feita em torno de referências a comportamentos observáveis no trabalho, a partir dos quais é possível diagnosticar a lacuna entre as competências necessárias à consecução dos objetivos organizacionais e as competências reais manifestadas, subsidiando, dessa forma, a tomada de decisão no desenvolvimento e na captação de profissionais e na prospecção de alianças e parcerias convergentes aos resultados organizacionais. A partir da identificação e do mapeamento das competências, recomendase a definição de um perfil, composto pelo conjunto de competências necessárias a determinado cargo em consonância com as informações obtidas do mesmo na profissiografia. Esse perfil pode ser indicado pelos CHAs (conhecimentos, habilidades e atitudes) isoladamente ou mesmo em interação, a partir do estabelecimento de parâmetros de investigação da expressão dessas competências (competências técnicas, que abarcam conhecimentos e habilidades específicas ao cargo, e competências comportamentais, que abrangem relações complexas entre habilidades relativas ao indivíduo e atitudes).

Entretanto, é preciso considerar que somente conhecimento técnico e qualificação do indivíduo, tratados isoladamente, não representam toda a noção de competência. Seu comportamento, em termos da manifestação de suas atitudes para com o trabalho, tende a manter relações de interdependência de efeitos na aquisição e na expressão das competências junto ao conhecimento técnico e suas habilidades. Assim, é possível considerar a competência apenas quando há competência em ação, ou seja, em saber ser e saber mobilizar o repertório individual em diferentes contextos envolvidos na situação de trabalho. Para Carbone, Brandão, Leite e Vilhena (2006), Dutra (2006) e Brandão e Borges-Andrade (2007), a identificação da competência só é efetiva quando há consistência dos três componentes cruciais: as competências do indivíduo, as demandas da tarefa e o ambiente organizacional.

Uma competência não pode ser compreendida de forma dissociada da ação, de modo que a aplicação correta de uma competência deve ser capaz de gerar resultados efetivos inseridos no escopo dos objetivos organizacionais mais amplos. As competências são, assim, reveladas enquanto as pessoas agem em face das situações profissionais com as quais se defrontam (Durand, 1998). Por isso, para se avaliar uma competência, são estabelecidos verbos que denotem ação ou desempenho, bem como critérios e condições de verificação das mesmas, com a definição de cada competência (Brandão \& Guimarães, 2001; Bruno-Faria \& Brandão, 2003; Brandão \& Bahry, 2005; Coelho Jr. et al., 2009).

Além de servir de base para os processos de seleção e de treinamento, o mapeamento de competências mostra-se como uma ferramenta para acompanhamento e avaliação dos resultados, servindo de mecanismo de feedback para a organização na medida em que se comparam eventuais desvios na execução de planos e indicadores de desempenho e os resultados efetivamente alcançados.

A identificação de competências no nível dos profissionais pode ser feita por 
meio de entrevistas comportamentais, isto é, com foco em comportamentos observáveis no ambiente de trabalho, ou por meio de grupos focais, compostos por colaboradores com desempenho diferenciado, preferencialmente de alta e média performance, e pode abranger toda a organização ou apenas determinadas áreas, funções ou cargos. O perfil de competências, resultado final do mapeamento, deve ser descrito por área, função ou cargo, e deve ser composto pelo título da competência, pela descrição do conceito e pelos indicadores de comportamentos observáveis para cada competência. É desse perfil de competências que se originam as demais práticas necessárias à gestão por competências, como a seleção, a avaliação de desempenho e as práticas de encarreiramento, dentre outras, pautadas nas competências mapeadas.

A implantação da gestão por competência nas organizações, especialmente nas de segurança pública, é um processo que exige o envolvimento de toda a organização, e deve contar com o apoio de toda a direção e dos colaboradores, conforme discutido por Leme (2005). Dessa forma, destaca-se a importância da prévia sensibilização e conscientização, assim como da atenção às especificidades de cada organização, uma vez que os ambientes social, cultural e político podem influenciar, diretamente, os efeitos provocados pela implementação do sistema de gestão por competência a ser adotado.

Por fim, é relevante compreender que as competências identificadas devem estar constantemente alinhadas à estratégia da organização, a fim de que não percam relevância ao longo do tempo e que o modelo preconizado tenha sido fundamentado em conceitos teóricos e práticos convergentes. Vale destacar que, para as empresas, é imprescindível a identificação de mecanismos que promovam de forma sustentada o desenvolvimento organizacional. Nesse sentido, essa tecnologia desenvolvida, aliando os métodos de análise profissiográfica ao mapeamento de competências, surge como uma alternativa metodológica capaz de suprir as necessidades das organizações no que se refere à implementação e à manutenção de políticas de gestão de pessoas.

Nesse sentido, a aplicação efetiva de uma competência é capaz de gerar um impacto significativo nos resultados individuais e estes, nos organizacionais. Igualmente, o mapeamento e a gestão por competências vêm se tornando ferramentas estratégicas fundamentais para as ações de gestão de pessoas, devendo ser sistematicamente planejados e executados nas organizações, com revisão contínua dos pressupostos teóricos e empíricos que os norteiam (Caetano, 2007; Coelho Jr. et al., 2009).

Diversas metodologias podem, portanto, ser utilizadas, desde que tenham elementos da própria organização como indicadores de competências e sejam desenvolvidas pautadas em conhecimento científico, baseadas no uso de métodos válidos. Ademais, para superar as dificuldades existentes na operacionalização e no estabelecimento de uma relação entre competência individual e organizacional, tornase necessário que a organização estabeleça políticas e estratégias claras de desenvolvimento de pessoas e de aprendizagem, formal ou informal, assim como um modelo difundido e compartilhado de gestão do conhecimento.

A gestão de competências pode ser considerada um importante instrumento para a identificação das necessidades de conhecimentos individuais e institucionais e para o consequente desenvolvimento das pessoas com vistas ao alcance dos resultados organizacionais, podendo ser utilizada tanto no setor privado quanto no setor público, por meio da aplicação de diferentes métodos, modelos, ferramentas e técnicas. O método deste trabalho é descrito a seguir. 


\section{Método}

O método incluiu a análise sistemática, por meio de categorias pré-definidas, de periódicos científicos das áreas de Administração e Psicologia classificados entre A1 e B2 no sistema qualis, da CAPES. A revisão de literatura realizada para fins de execução deste trabalho compreendeu periódicos científicos das áreas de Administração e Psicologia, entre os anos 2000 e 2009. Essa revisão foi realizada visando a subsidiar e a dar sustentação às afirmações contidas neste trabalho, especialmente no que tange à necessidade de incorporar as metodologias de mapeamento de análise profissiográfica e de mapeamento de competências em torno da maximização do desempenho competente dos indivíduos em situação de trabalho em instituições de segurança pública.

Foram investigadas as publicações disponibilizadas nessa literatura por meio das palavras-chave, isoladas ou em interação, competências e profissiografia. Esse levantamento foi fundamental para a verificação empírica quanto ao estado da arte em comportamento organizacional no que se refere ao ineditismo proposto neste trabalho.

Os critérios de escolha dos periódicos foram os seguintes: os periódicos, nacionais, deveriam ser indexados e apresentar conceituação avaliativa entre os níveis de impacto A1 a B2, à época de análise e interpretação dos dados coletados. Não foram incluídas publicações do ano 2010, posto que muitos periódicos estavam com a publicação atrasada quando da realização deste trabalho.

Os resultados serão apresentados a seguir, à luz do objetivo norteador deste trabalho, a saber, discutir sobre uma metodologia de análise profissiográfica desenvolvida conjuntamente com ações diagnósticas voltadas para o mapeamento de competências necessárias ao desempenho competente das atribuições, com foco no escopo das organizações de segurança pública.

\section{Resultados}

Uma importante constatação identificada após análise de literatura referente à análise profissiográfica e ao mapeamento de competências é que não foram encontradas referências disponíveis quanto ao termo profissiografia de forma conjunta ao termo mapeamento de competências. Os artigos analisados quanto à palavra-chave competência referiam-se, normalmente, à proposição de metodologia(s) específica(s) de gestão por competências, abarcando, inclusive, a etapa de mapeamento. Os relatos verificados, especialmente os teóricos, como o de Brandão e Borges-Andrade (2007), dizem respeito à apresentação e à discussão sobre a gestão por competências e sua relação com outras variáveis em comportamento organizacional, ou mesmo tratam da necessidade de se efetuar uma limpeza conceitual nesse campo de atuação, operacionalizando-se, de forma mais sistemática, o construto competências. Pode ser que não tenham sido encontradas referências científicas tratando das relações entre profissiografia e mapeamento de competências de forma conjunta em função de essas duas práticas e sua abordagem pela literatura pertencerem a momentos históricos diferentes no Brasil, já que o método de análise profissiográfica é anterior ao mapeamento de competências. Aponta-se, então, como produto deste trabalho, a relevância e a eficácia da utilização conjunta das duas metodologias para a realidade das organizações brasileiras. Outra justificativa refere-se ao provável uso isolado de uma prática independentemente da outra, sem qualquer tipo de vinculação ou relação entre elas. O próprio universo de pesquisas científicas na área de segurança pública, no Brasil, ainda necessita ser mais bem explorado. 
Já os relatos empíricos, como os de Veiga, Leite e Duarte (2005) e os de Mello, Leão e Paiva Jr. (2006), dizem respeito à validação psicométrica de medidas ou à identificação de preditores relacionados à aquisição e à expressão de competências no trabalho. Modelos empíricos, como o de Brandão (2009), podem ser voltados para a investigação de variáveis relacionadas à aquisição e à expressão de competências. Nenhum desses modelos faz referência à análise profissiográfica. Assim, a literatura, em geral, tende a enfocar a descrição de procedimentos necessários à implementação e à supervisão das etapas de gestão.

Em linhas gerais, a metodologia de mapeamento de competências vem sendo implementada nas organizações, fundamentalmente, visando a identificar e a extrair competências profissionais relevantes ao adequado desempenho no trabalho. O mapeamento vem sendo considerado uma das etapas constitutivas da gestão por competências. A partir desse mapeamento, ou seja, da identificação das competências necessárias, torna-se possível efetuar um diagnóstico das competências profissionais, ou seja, identificar o gap ou a lacuna de competências existentes entre aquelas que são necessárias para o cumprimento dos objetivos organizacionais e aquelas que o indivíduo executa (Brandão \& Bahry, 2005; Brandão \& Borges-Andrade, 2007; Cardoso Filho, 2003).

Isso posto, e utilizando como base a análise da literatura realizada na área, a proposta deste trabalho é que o mapeamento das competências técnicas, proximais ao cargo e diretamente relacionadas ao grau de conhecimento e de habilidades de seu ocupante, e as comportamentais, relacionadas a habilidades genéricas ou distais ao cargo e atitudes necessárias, é de fundamental valia para o desempenho competente de determinado cargo em instituições de segurança pública. Esse mapeamento deve ser realizado em consonância com a análise profissiográfica, isso porque, no contexto da profissiografia, considera-se que sua aplicação vá além das medidas de desempenho no trabalho, visto que as competências são descritas e identificadas como comportamentos objetivos, tangíveis e observáveis no ambiente de trabalho, facilitando, assim, as ações de planejamento, monitoramento, supervisão e redesenho do trabalho. Nesse sentido, pode-se investir no desenvolvimento ou na formação daqueles que precisam expressá-las, ou mesmo na seleção de profissionais que já apresentem essas competências sem perder de vista aspectos relacionados à tarefa e ao contexto de trabalho (facilitadores e restritivos), tal como a análise profissiográfica permite identificar.

Ações de gestão precisam ser efetivamente planejadas e desenvolvidas pelas instituições de segurança pública, em termos, principalmente, de um acompanhamento e monitoramento efetivo do policial durante os anos de seu trabalho, já que o contexto organizacional é de suma relevância no comportamento do trabalhador. A criação de uma cultura organizacional favorável, dessa forma, é fundamental, e ações de desenvolvimento do mesmo, especialmente no provimento de suporte organizacional ao desempenho, também devem ser planejadas para o policial, daí o mapeamento de competências ser capaz de prover importantes insumos a ações diversas na área de gestão de pessoas. É importante ressaltar, novamente, que é preciso que se crie uma cultura de valorização profissional nessas instituições não apenas sob o ponto de vista de suas condições de trabalho, como salário e benefícios recebidos, mas também de desenvolvimento de suas competências alinhadas à sua área de atuação. Essa cultura passa, também, pela sensibilização de gestores e do staff dos órgãos acerca da importância de se trabalhar 
com competências e de seu real impacto nos resultados de trabalho.

Um dos principais desafios enfrentados na área de avaliação psicológica no contexto de segurança pública no Brasil, bem como na continuidade dos processos que antecedem ou sucedem essa fase nas instituições, consiste na escassez ou na ausência de pesquisas científicas ou de documentos válidos que deem base para um conhecimento real do cargo demandado. Outro grande desafio consiste em solucionar problemas na gestão da avaliação psicológica no âmbito das organizações, especialmente em termos da existência de processos dissociados entre si, que não são vinculados uns aos outros, desde a seleção de um policial até o processo do curso de formação e do acompanhamento desse indivíduo já em sua atuação profissional. A integração de políticas de recursos humanos voltadas para a capacitação contínua e o desenvolvimento desse tipo de profissional é mais que necessária ao desempenho competente de suas atribuições.

Outro aspecto importante a ser ressaltado sobre as contingências atuais do modus operandi das organizações de segurança pública refere-se ao fato de que se vive em uma realidade social e econômica em que os processos de emprego e estabilidade não são necessariamente galgados por vocação, mas sim, por necessidade ou por escolha financeira. Tal fato impõe a cada uma das instituições o desafio de lidar com algumas adversidades decorrentes da falta de alinhamento entre o perfil exigido pelo cargo e a consequente falta de consistência na formação desse candidato, na sua vocação ou mesmo nas suas competências para a realização de determinadas tarefas demandadas no cargo. E, em se tratando de cargos que contemplam tarefas que trazem algum grau de risco de vida para o indivíduo, para a sociedade ou mesmo para parceiros de trabalho, torna-se ainda mais evidente a necessidade de que esse cargo, e o perfil de seus ocupantes, sejam ainda mais bem estudados em termos do perfil de competências técnicas e comportamentais relacionadas ao seu adequado desempenho.

Afinal, que policial é esse que está sendo demandado na etapa de seleção, levando-se em conta as especificidades da instituição e do local? Que perfil ele deve apresentar para ingressar na corporação, de forma que suas características psicológicas sejam, pelo menos, compatíveis com as necessidades do cargo? Que preparação ele deve ter? Tendo sido aprovado no certame, que outras características não se mostraram adequadas na avaliação psicológica e merecem certo grau de acompanhamento por parte de uma equipe multidisciplinar? Durante o curso de formação, há um acompanhamento sistematizado desse aluno, de forma a validar o processo de entrada e, ainda, de prover subsídios para um real monitoramento, antevendo possibilidades de desempenho no cargo? Essas são questões fundamentais que merecem reflexão por parte dos profissionais da área de recursos humanos e, também, dos grandes dirigentes das organizações de segurança pública.

Futuramente, espera-se que o presente trabalho sirva como parâmetro para o planejamento e a execução de futuras adequações na realidade de instituições de segurança pública que ainda não realizaram estudos científicos para compreender a dinâmica das necessidades de seus cargos e ocupantes (Moura \& Pasquali, 2007). Espera-se que a realidade atual de algumas instituições de segurança pública, que já adotam modelos de gestão por competências alinhados às informações obtidas nas análises profissiográficas de seus cargos, seja generalizada a todas elas, e o compartilhamento de tais informações é imprescindível para a profissionalização da gestão de pessoas em seu contexto. 


\section{Considerações finais}

O presente trabalho objetivou discutir questões de natureza metodológica e implicações práticas decorrentes da aplicação das ferramentas de profissiografia e de mapeamento de competências no contexto das instituições de segurança pública. A partir da análise na literatura em comportamento organizacional sobre profissiografia e competências, propôs-se, neste trabalho, uma articulação teórica e prática relacionada à integração entre essas duas variáveis, com foco em uma metodologia de mapeamento de atribuições e competências a ser aplicada no contexto das organizações de trabalho, especialmente as de segurança pública. Como não foram encontradas referências disponíveis na literatura voltadas para a proposição de uma metodologia de mapeamento de competências alinhada à atividade de profissiografia, este trabalho teve como foco o alinhamento dessas duas metodologias.

Verificou-se que diferentes propostas metodológicas de profissiografias e de mapeamento de competências vêm sendo desenvolvidas e utilizadas de forma isolada, como exigência mínima para subsidiar processos seletivos e avaliações psicológicas no contexto da segurança pública realizadas no Brasil, assim como contemplado na Resolução no 01/2002, do Conselho Federal de Psicologia, e no Decreto no 7.308. Tal prática indica a busca por melhorias dos processos seletivos, bem como dos cursos de formação, das matrizes curriculares e do ambiente de trabalho como um todo.

Em relação à literatura de gestão de competências voltada especificamente para a área policial e para o setor de segurança pública, verificou-se que, no Brasil, praticamente inexistem estudos nesse sentido. Há muitas pesquisas voltadas para a competência policial em sentido jurídico, focadas apenas no mérito da técnica de execução de seus afazeres, com pouca ou nenhuma ênfase no aspecto comportamental no desempenho de suas atribuições, como apresentado neste trabalho. No entanto, percebe-se que uma reforma, de natureza cultural e de gestão, está ocorrendo em algumas de nossas instituições de segurança pública, especialmente em termos do realinhamento de políticas de gestão de pessoas que valorizem as competências necessárias ao desempenho competente das atribuições. Assim como as empresas, o Estado está se conscientizando de que investir e valorizar o capital humano das instituições poderá fazer a diferença no enfrentamento à criminalidade.

É possível notar que os governos, nas esferas federal, estadual e municipal, têm se esforçado para investir mais recursos na área de segurança, em ações que vão desde a valorização e a educação profissional até a aquisição de material adequado ao trabalho do profissional da área. Essas mudanças trazem um novo conceito de se planejar e de se desenvolver ações de segurança pública, comprometido com os direitos humanos e fundamentado no saber acumulado e nos avanços científicos.

Espera-se, ainda, que as instituições de segurança pública, por meio de suas políticas e práticas de valorização, passem a disseminar entre si, incentivando-se ações de benchmarking, informações concernentes a modos de gestão do fator humano no trabalho, especialmente no que concerne o desenvolvimento de competência e na análise de fatores situacionais de restrição e/ou apoio ao desempenho. Muitas das situações com as quais essas instituições têm que lidar no dia a dia passam pela compreensão de fatores relacionados ao indivíduo, à tarefa e ao contexto de trabalho. Lançar mão de ferramentas e técnicas científicas, que criem condições facilitadoras à gestão considerando a realidade dessas instituições, é o desafio. Para isso, mais do que alterar e redesenhar estruturas organizacionais que, muitas vezes, 
não geram o impacto esperado nas rotinas de trabalho torna-se premente o monitoramento e a capacitação contínua dos profissionais e equipes em torno do reforçamento ao desempenho laboral competente.

A valorização do profissional de segurança, não necessariamente pecuniária, é a base para um serviço de qualidade junto à sociedade, pois, notadamente, tem-se percebido a mudança de comportamento dos cidadãos frente ao atendimento policial. É claro que há ainda muito por fazer, porém algumas mudanças que já ocorreram podem ser percebidas na sociedade e pelos profissionais da área de segurança.

O trabalho preventivo e as parcerias entre as instituições de segurança e a comunidade já têm propiciado mudanças significativas. Dessa forma, a participação popular indica caminhos alternativos a serem seguidos, especialmente em termos de projetos, como o planejamento de ações de polícia comunitária, e em termos da necessidade constante da busca de melhoria e de aperfeiçoamento dos mecanismos de gestão da atividade policial e de segurança pública. Ainda é preciso avançar mais em termos de deveres, direitos, estrutura e agilidade operacional e na participação social e comunitária, mas o que já se vê hoje, certamente, possibilita antever e pressupor que a área da segurança pública esteja passando, efetivamente, por mudanças de gestão. É fundamental que, por meio da aplicação da profissiografia e do mapeamento de competências, se possa selecionar pessoas que, de fato, apresentem os requisitos necessários ao bom desempenho de seus cargos e tenham como meta atender, servir e proteger o cidadão.

As duas metodologias podem ser colocadas em prática conjuntamente por meio do estudo científico das atribuições e das responsabilidades dos cargos, da descrição detalhada das atividades e tarefas, da identificação dos conhecimentos, das habilidades e das características pessoais necessárias para sua execução e identificação de características restritivas ou impeditivas para o cargo. As implicações práticas dessas ferramentas no contexto das organizações não se restringem à área de seleção, mas podem ser aplicadas ao planejamento estratégico da organização, ao fornecimento de insumo para ações de intervenção na estrutura da organização, ao incremento do capital humano no trabalho, ao subsídio para cursos de capacitação e formação e ao auxílio na área de treinamento e desenvolvimento, dentre outras aplicabilidades.

O perfil profissiográfico deve, assim, considerando os resultados obtidos com o mapeamento de competências, ser válido e consistente para a elaboração de ações educacionais no âmbito das organizações, tamanha a riqueza das informações coletadas que podem subsidiar tais práticas aprendizes no trabalho.

É importante destacar que a análise do perfil profissiográfico dos cargos e o mapeamento das competências devem ser atualizados periodicamente nas instituições, posto que os processos de trabalho nas organizações são dinâmicos e precisam ser constantemente revistos. Dessa forma, verifica-se que os resultados do mapeamento de competências são essenciais para a consolidação do perfil profisiográfico, e devem, assim, ser considerados táticos ou estratégicos ao desempenho das instituições de segurança pública. 


\section{Cristiane Faiad}

Doutora pela Universidade de Brasília. Professora da Universidade Salgado de Oliveira, Niterói - Rio de Janeiro - RJ.

E-mail: crisfaiad@gmail.com

\section{Francisco Antonio Coelho Junior}

Doutor. Professor da Universidade de Brasília, Brasília - DF.

E-mail: acoelho@unb.br

\section{Patrícia Fagundes Caetano}

Mestre em Psicologia pela Universidade de Brasília. Especialista em avaliação psicológica da Universidade de Brasília, Brasília - DF.

E-mail: patriciafag@gmail.com

\section{Anelise Salazar Albuquerque}

Doutora pela Universidade de Brasília. Prestadora de serviço da Universidade de Brasília e Professor do Instituto de Educação Superior de Brasília, Brasília - DF.

E-mail: anesalazar@uol.com.br

\section{Endereço para envio de correspondência:}

UNIVERSO - Programa de Mestrado em Psicologia.

Rua Marechal Deodoro, $\mathrm{n}^{\circ} 17,2^{\circ}$ andar, Cenntro, Niterói - Rio de Janeiro - RJ - Brasil. CEP: 24030060

Recebido 8/11/2010, 1aㅡ Reformulação 24/10/2011, Aprovado 10/1/2012.

Referências

Ávila-Batista, A. C. (2011). Construção e estudos psicométricos de uma escala para avaliação da impulsividade. Dissertação de mestrado. Programa de Pós-Graduação em Psicologia, Universidade São Francisco, São Paulo.

Borges, C. E. M. (2009). Gestão de recursos humanos: sua importância aplicada à segurança pública. (Artigo apresentado ao Núcleo de Educação Continuada e Pós-Graduação da Faculdade Fortium), Brasília, DF.

Brandão, H. P., \& Bahry, C. P. (2005). Gestão por competências: métodos e técnicas para mapeamento de competências. Revista do Serviço Público Brasília, 56(2), 179-194.

Brandão, H. P., \& Borges-Andrade, J. (2007). Causas e efeitos da expressão de competências no trabalho: para entender melhor a noção de competência. Revista de Administração Mackenzie, 8(3), 32-49.
Brandão, H. P., \& Guimarães, T. A. (2001). Gestão de competências e gestão de desempenho: tecnologias distintas ou instrumentos de um mesmo construto? RAE, 41(1), 8-15.

Brandão, H. P., \& Guimarães, T. A. (2002). Gestão de competências e gestão de desempenho. In T. Wood Jr. (Org.), Gestão empresarial: o fator humano. São Paulo: Atlas.

Brandão, H. P. (2009). Aprendizagem, contexto, competência e desempenho: um estudo multinível. Tese de doutorado. Instituto de Psicologia. Universidade de Brasília, Brasília, DF.

Brannick, M. T., Levine, E. L., \& Morgeson, F. P. (2002). Job and work analysis: Methods, research, and applications for human resource management. California: SAGE Publications.

Brasil. Decreto que regulamenta concursos ganha regras sobre avaliação psicológica de candidatos. Recuperado em outubro, 2010 de http://www.planejamento.gov.br/noticia. asp?p $=\operatorname{not} \& \operatorname{cod}=6636 \&$ cat $=34 \&$ sec $=6$ 
Bruno-Faria, M. F., \& Brandão, H. P. (2003). Competências relevantes a profissionais da área de T\&D de uma organização pública do Distrito Federal. Revista de Administração Contemporânea, 7(3), 35-56.

Caetano, P. F. (2007). Construção e validação do inventário de competências pessoais para o trabalho - ICPT. Dissertação de Mestrado. Instituto de Psicologia. Universidade de Brasília, Brasília, DF.

Carbone, P. P., Brandão, H. P., Leite, J. B. D., \& Vilhena, R. M. P. (2006). Gestão por competência e gestão do conhecimento (2a ed.). Rio de Janeiro: Editora FGV.

Cardoso Filho, J. C. (2003). Identificação de competências individuais em atividade de fiscalização e controle externo na Câmara Legislativa do Distrito Federal. Dissertação de mestrado. Departamento de Ciência da Informação, Universidade de Brasília, Brasília, DF.

Coelho Jr., F. A., \& Borges-Andrade, J. E. (2008). Uso do conceito de aprendizagem em estudos relacionados ao trabalho e organizações. Paidéia, 18(40), 221-234.

Coelho Jr., F. A., Moura, C. F., Caetano, P. F., \& Albuquerque, A. S. (2009). Aplicações da profissiografia e mapeamento de competências. (Manuscrito não publicado).

Dezinot, A. E. R. (2003). Descrição e análise de cargos e suas contribuições na interface da gestão de pessoas com a saúde e a segurança do trabalho. Dissertação de mestrado, Curso de Pós-Graduação em Sistemas de Gestão, Universidade Federal Fluminense, Niterói, RJ.

Durand, T. (1998). Forms of incompetence. Proceedings of the fourth international conference on competence-based management. Oslo: Norwegian School of Management.

Dutra, J. S. (2006). Gestão de pessoas: modelo, processos, tendências e perspectivas. São Paulo: Atlas.

Dutra, J. S., Hipólito, J. A. M., \& Silva, C. M. (2000). Gestão de Pessoas por competência: o caso de uma empresa de telecomunicações. Revista de Administração Contemporânea, 4(1), 161-176.

Freitas, L. C. de O. (2004). Avaliação psicológica em concurso público: relações com o desempenho em treinamento de bombeiros. Dissertação de mestrado, Instituto de Psicologia, Universidade de Brasília, Brasília, DF.

Leme, R. (2005). Aplicação prática de gestão de pessoas por competência: mapeamento, treinamento, seleção, avaliação e mensuração de resultados de treinamento. Rio de Janeiro: Qualitymark.

Mello, S. C. B., Leão, A. L. M. S., \& Paiva Jr., F. G.. (2006), Competências empreendedoras de dirigentes de empresas brasileiras de médio e grande porte que atuam em serviços da nova economia. Revista de Administração Contemporânea, 10(4),47-69.

Moura, C. F. (2009). Análise profissiográfica. (Manuscrito não publicado).

Moura, C. F., \& Caetano, P. F. (2007). Profissiografia dos soldados bombeiros militares do corpo de bombeiro do Distrito Federal. Brasília, DF: LabPAM. (Documento interno do CBMDF).

Moura, C. F., \& Pasquali, L. (2007). Análise profissiográfica: uma proposta metodológica. Trabalho apresentado no $31^{\circ}$ Congresso Interamericano de Psicologia, Ciudad de México.
Moura, C. F., Caetano, P. F., Braga, J. L., Pasquali, L., Reis, M. S., \& Oliveira, S. H. T. (2007). Profissiografia do soldado policial militar do Estado do Rio de Janeiro. Brasília, DF: LabPAM. (Documento interno da PMERJ).

Pasquali, L., Cabral, A. R., Figueira, K. S., Rodrigues, M. M. M., \& Moura, C. F. (2002). Profissiografia do cargo de agente de polícia civil do Distrito Federal. Recuperado em outubro, 2010 de http://portal.mj.gov.br/main.asp?Team=\%7B21F842C5A1C3-4460-8A48-83F441C4808C\%7D.

Pasquali, L. (1997). Planejamento e avaliação de ações de IEC - Manual Prático de Planejamento Estratégico. Brasília, DF: Ministério da Saúde/Informação, Educação e Comunicação.

Pasquali, L., Albuquerque, A. S., Freitas, L. C. O., Barbosa, B., \& Roldão, A. C. (2002). Profissiografia do cargo de policial rodoviário da polícia rodoviária federal. Documento Brasília,DF: LabPAM. (Documento interno da PMERJ).

Pasquali, L., Moura, C. F., \& Freitas, L. C. O. (2010). Análise profissiográfica. In L. Pasquali, (Org), Instrumentação psicológica: fundamentos e práticas. Porto Alegre: Artmed.

Prahalad, C. K., \& Hamel, G. (1995). Competindo para o futuro. Rio de Janeiro: Campus.

Ramon, R. (1992). Avaliação psicológica e sua aplicação prática. Recuperado em outubro, $2010 \mathrm{de} \mathrm{http://carreiras.}$ empregos.com.br/comunidades/rh/artigos/170105-avaliacao_ psicologica.shtm

Sampaio, J. R. (2006). Perfil profissiográfico: uma comparação entre a experiência norte-americana e a brasileira. In I. B. Goulart (Org), Temas de psicologia e administração. São Paulo: Casa do Psicólogo.

SENASP. (2008). Projeto de qualidade de vida: guia de ações. São Paulo: DEPAID/SENASP/MJ.

Spector, P. E. (2003). Psicologia nas organizações. São Paulo: Saraiva.

Thadeu, S. H. (2011). A validade da avaliação psicológica em um processo seletivo na área de segurança pública. Dissertação de mestrado, Programa de Pós-Graduação em Psicologia, Universidade Salgado de Oliveira, RJ.

Thadeu, S. H., Reis, M. S., Moura, C. F., Caetano, P. F., Braga, J. L., \& Pasquali, L. (2008). Profissiografia dos soldados policiais militares da polícia militar do Estado do Rio de Janeiro, Brasil. In 13 Conferência Internacional de Avaliação Psicológica, Portugal.

Vasconcelos, A. G. (2010). Evidências de validade preditiva de medidas psicológicas em relação ao desempenho no trabalho: um estudo de caso em uma organização militar. Dissertação de mestrado, Programa de Pós-Graduação em Psicologia, Universidade Federal de Minas Gerais, Belo Horizonte.

Veiga, L., Leite, M. R. S. D. T., \& Duarte, V. C. (2005). Qualificação, competência técnica e inovação no ofício docente para a melhoria da qualidade do ensino fundamental. Revista de Administração Contemporânea, 9(3), 143-167. 